\title{
Effect of Blending Ratio of Fibers on the Properties of Nonwoven Fabrics Based of Alfa Fibers
}

\author{
Lassaad Ghali, Mohamed Taher Halimi, Mohamed Ben Hassen, Faouzi Sakli \\ Textile Engineering Laboratory, Monastir University, Monastir, Tunisia \\ Email: ghali las@yahoo.fr
}

Received 28 April 2014; revised 3 June 2014; accepted 10 June 2014

Copyright (C) 2014 by authors and Scientific Research Publishing Inc.

This work is licensed under the Creative Commons Attribution International License (CC BY). http://creativecommons.org/licenses/by/4.0/

(c) (i) Open Access

\begin{abstract}
Natural fibers are nowadays increasingly employed for making nonwoven, replacing the synthetic materials due to economic and environmental considerations. In this setting, we examine the use of Alfa fibers in nonwoven. Extracted Alfa fibers present satisfying mechanical properties that allow them to be used to produce nonwoven textiles materials. Therefore, Alfa fibers are, mainly, blended with cotton, polyester, Tencel and wool. Webs are prepared using cotton or wool cards in regular width. The nonwoven consolidation is made by needle-punching method. The weight, thickness, air permeability, adiathermic capacity and tensile properties are investigated. The results exhibit that the air permeability increases with the increase of Alfa fibers ratio for the nonwoven Alfa blended with short fibers. It decreases in case of Alfa/Wool blend. We can conclude also that the nonwoven Alfa blended with wool fibers have the highest properties values for all the Alfa fibers blends. Data also revealed that the tensile properties are reduced with the increment of Alfa fibers ratio.
\end{abstract}

Keywords

Alfa Fibers, Nonwoven, Air Permeability, Specific Strength

\section{Introduction}

The nonwoven fabrics were exploited in a large number of applications such as membrane [1], reinforcing fibers [2] [3], biomedical devices [4] and scaffold for tissue engineering [5]. Raw materials used in nonwoven products vary greatly, covering the entire spectrum from synthetic to natural fibers [6] [7]. Besides, current research all over the word is concerned with the development of new uses and added value to farm and forestry products for 
greater economic benefits such as filters applications [7]-[9]. A lot of recent works have focused on developing products from Alfa fibers such as reinforcement in biodegradable composite [10]-[14]. For example, Triki et al. [13] have characterized the adhesion of nonwoven Alfa fibers in unsaturated polyester matrix. Omri et al. [14] have studied the effect of wool and thermo-binder fibers on adhesion of Alfa fibers in unsaturated polyester matrix. To our knowledge, no data has concerned the study of physical and mechanical properties of needlepunched Alfa blended fibers nonwoven. In this setting, this study of nonwovens based on blend fibers with Alfa was made.

Alfa fibers are extracted from the plant Stippa tenacissima, or esparto grass (Alfa is the Arab name for esparto), and grows in the dry regions of North Africa [15]. These fibers are, extensively, used in the production of paper. Given that this plant is very available in Tunisia and in order to make it a successful alternative crop, it must be incorporated into value-added products such as nonwoven for domestic textiles materials.

Besides, the use of Alfa separated fibers in nonwoven is related to the nonwoven process, the machinery parameters, the quality of fibers and the quality of nonwoven to be produced. Obviously, the machinery process depends on the way to consolidate the fibrous structure which can be mechanical, chemical or thermal consolidation [16] [17]. The nonwoven mechanical properties are mainly depended on the machinery parameters particularly for mechanical consolidation by needle-punching.

The needle gauge, the needling density, the needle penetration and the passage number present also an important affect on the nonwoven thickness, weight, density and tensile properties [16] [18]-[21]. Thus, the fiber quality has an important effect on the nonwoven properties. One of the limitations of the extensive use of natural fibers in nonwovens is their low strength if the web is not bonded with a screen of synthetic fibers. Certainly, the requirements of quality imposed in the finished products allow the use of a tiny quantity of natural fibers in nonwoven.

Herein, our focus deals with the characterization of needle-punched nonwoven made with Alfa fibers blended with various fibers. The effect of Alfa fiber ratio on the air permeability, adiathermic capacity and mechanical properties of nonwoven are discussed.

\section{Materials and Methods}

\subsection{Alfa Fibers Extraction}

The raw material used in this study is collected from Kasserine region in Tunisia during the summer season when the leaves of esparto (Alfa) reach their maximum state of growth.

To extract Alfa fibers from the organic matrix, three stages were considered. Firstly, the leaves were separated from stalks by manual cutting. Secondly, they were immersed in caustic soda solution $(\mathrm{NaOH}, 3 \mathrm{~N})$ during two hours at a temperature of $100^{\circ} \mathrm{C}$. The details of extraction process were described in our previous work [22]. Then they were subjected to bleaching treatment and air dried (Figure 1). After this chemical treatment, technical fibers were not sufficiently separated. For this reason, fibers were finally separated (Figure 2) from leaves by a mechanical treatment using the trash tester Shirley analyzer (Figure 3) during four passages.

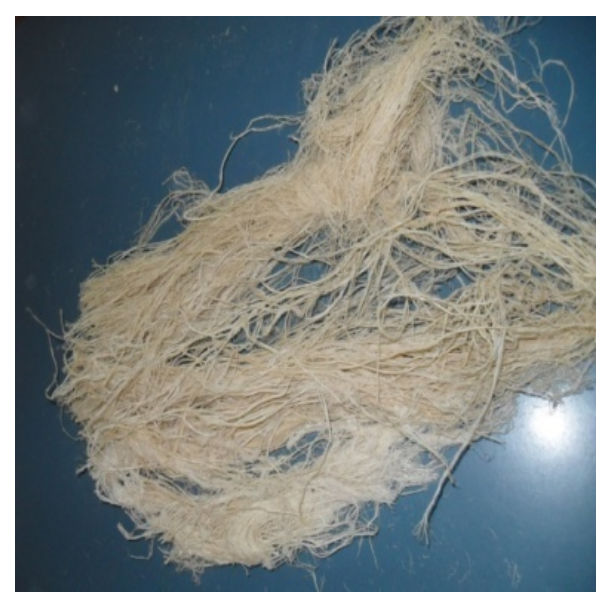

Figure 1. Alfa fibers after chemical treatment. 


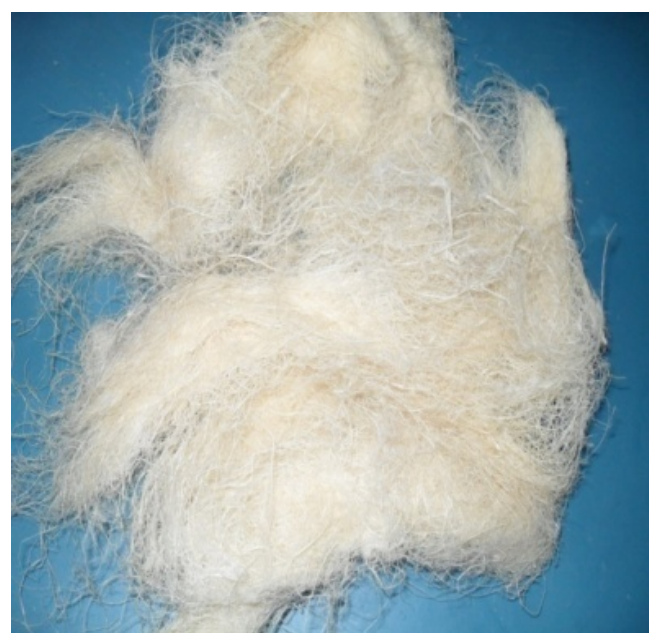

Figure 2. Alfa fibers after mechanical treatment.

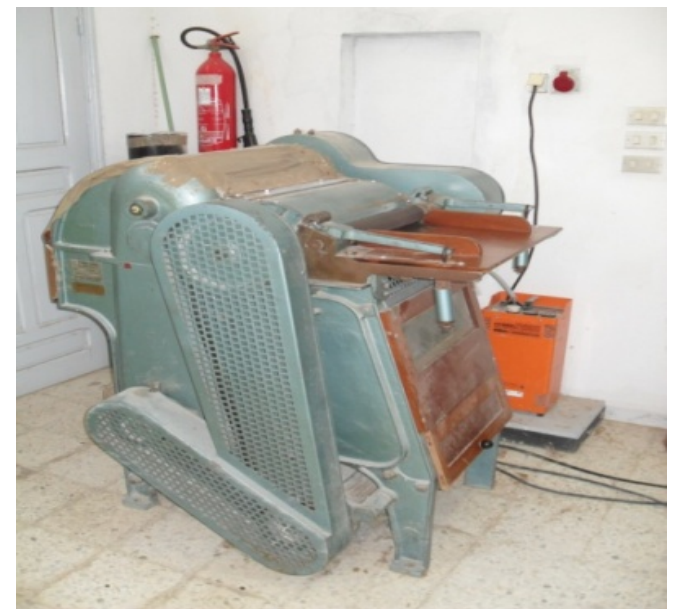

Figure 3. Shirley analyzer apparatus.

\subsection{Materials Properties and Mixture}

The overall properties of nonwoven are mainly related to fibers characteristics and the manufacturing process. In order to improve fibers cohesion, Alfa fibers were mixed with different fibers such us: cotton, polyester, tencel and wool. Table 1 presents the main properties of the different fibers. The ratio of Alfa fibers in nonwoven takes seven levels varying from $0 \%$ to $60 \%$.

\subsection{Preparation of Needle-Punched Nonwoven Fabric}

The preparation of needle-punched nonwoven fabric was performed in four steps. In the first step, the openers ensure the raw material opening, cleaning and blending and supply regularly the carding machine. The fiber mixtures were run through the opener two times in order to improve the homogeneity of the blend. In the second step, blended fibers were carded with wool carding machine in the case of Alfa/Wool blend or cotton carding machine in the others cases in order to remove dirt particles, fiber alignment and web formation. The consolidation of the nonwoven fabric is provided by Needle-punching method. This method consists of mechanically interlocking fibers by repeatedly punching through the fiber web with an array of barbed needles (Figure 4). Typically, needling is used to consolidate a fibrous structure, to densify it and control the porosity [16].

The needling parameters are presented in Table 2 . All studied fibers webs are subjected to four needling passages to ensure good consolidation. The Figure 5 and Figure 6 present an Alfa/Tencel, Alfa/cotton, Alfa/PES and Alfa/wool nonwoven fabric, respectively. 
Table 1. Characteristics of the used fibers.

\begin{tabular}{cccccc}
\hline Fiber properties & Cotton & PES & Tencel & Alfa & Wool \\
\hline Fiber tenacity $(\mathrm{cN} / \mathrm{tex})$ & 31.1 & 45.8 & 37 & 29.24 & 25.77 \\
Fiber elongation $(\%)$ & 8.9 & 13 & 13 & 26.99 & 11.98 \\
Mean length $(\mathrm{mm})$ & 24.8 & 38 & 38 & 41 & 52 \\
Fineness $\left(10^{-3} \mathrm{Tex}\right)$ & 172 & 150 & 170 & $\approx 15.66 * 103$ & $\approx 1424.5$ \\
Diameter $(\mu \mathrm{m})$ & - & - & - & 122 & 37.21 \\
Density $\left(\mathrm{g} / \mathrm{cm}^{3}\right)$ & 1.51 & 1.32 & - & 1.34 & 1.31 \\
\hline
\end{tabular}

Table 2. Needling parameters.

\begin{tabular}{ccc}
\hline Parameters & Value \\
\hline Passage number & 4 \\
Layer number & 1 \\
Punching density (needle $\left./ \mathrm{cm}^{2}\right)$ & 0.49 \\
Penetration depth $(\mathrm{cm})$ & 3 \\
\hline
\end{tabular}

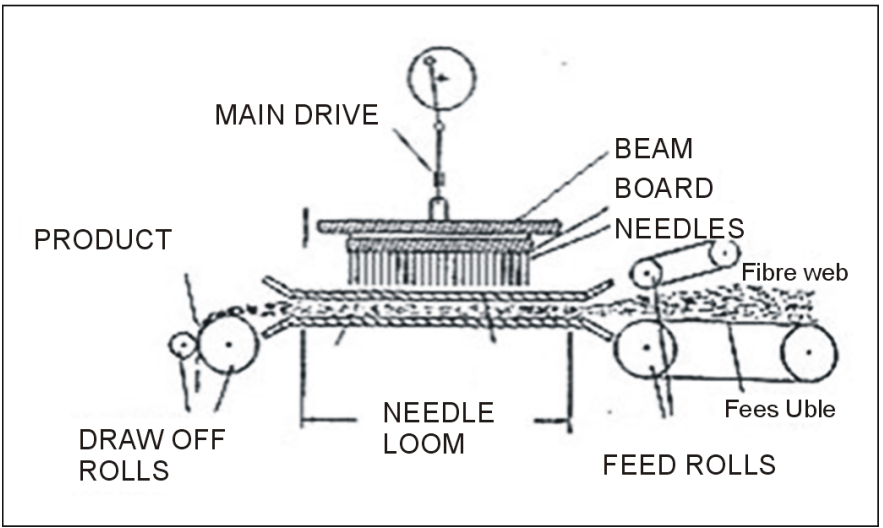

Figure 4. Needle-punching principle.

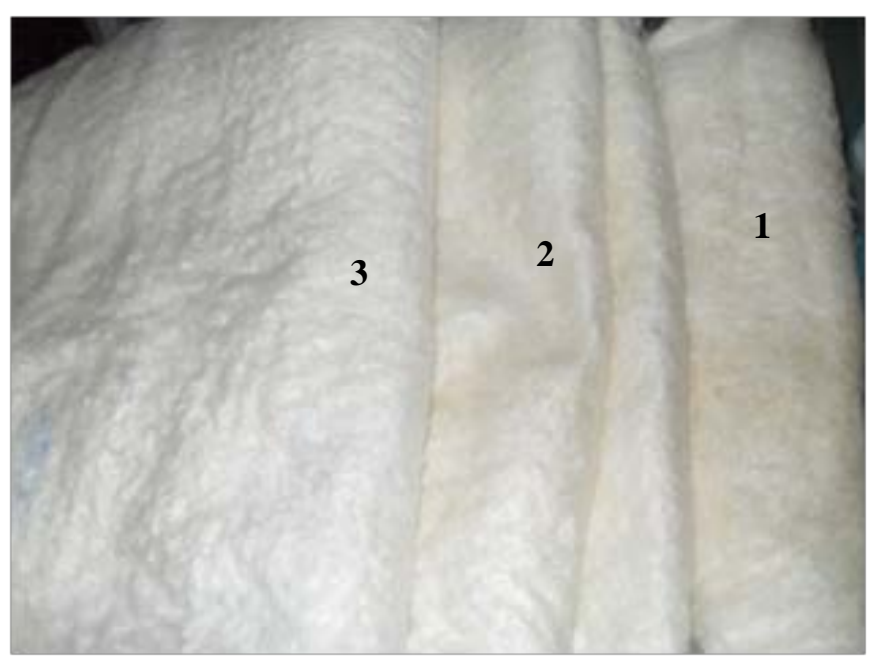

Figure 5. Nonwoven from: (1) Alfa/Tencel, (2) Alfa/Cotton, and (3) Alfa/PES. 


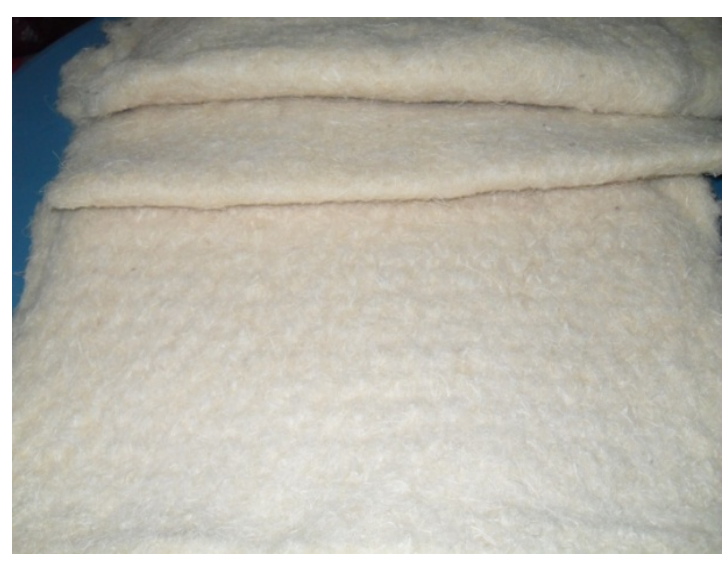

Figure 6. Nonwoven from Alfa/Wool.

\subsection{Testing and Evaluation}

Nonwoven characterization was done according to standard ISO recommended methods. The mechanical properties including breaking strength and elongation were determined using ISO 13934-1(1999) standard. The physical properties including weight, thickness, air permeability and the adiathermic capacity were identified, respectively, according to ISO 9073 (1989), ISO 5084 (1996), ISO 9237 (1995) and NF G 07-107 standards.

Nonwoven samples were randomly cut $\left(100 \mathrm{~cm}^{2}\right)$ and conditioned in a standard atmosphere $(65 \% \mathrm{RH}$ and $20^{\circ} \mathrm{C}$ ) before the determination of weight and thickness. The measurement was repeated 10 times for each test.

An Instron Tensile Testing Machine was used to measure the tensile properties of needle-punched nonwoven fabrics. The nonwoven tenacity was determined according to equation [23]:

$$
\text { specific strength }\left(\mathrm{N} / \mathrm{g} / \mathrm{cm}^{3}\right)=\frac{\text { Breaking load }(\mathrm{N})}{\text { Fabric density }\left(\mathrm{g} / \mathrm{cm}^{3}\right)}
$$

A mean of ten test results has been calculated in each direction (MD: machine direction, CD: cross direction). The air permeability of nonwoven, expressed in $\left(\mathrm{L} / \mathrm{m}^{2} / \mathrm{s}\right)$ was measured using air permeability tester (TEXTEST FX 3300).

\section{Results and Discussions}

A nonwoven was characterized by different physical parameters such as: weight, thickness, air permeability and adiathermic capacity. These characteristics depend essentially on needling machine parameters such as needle gauge, punch density and depth needle penetration [9] [16] and [19]. The composition of the fiber blend has also an important influence in the properties of nonwoven.

In addition, the requirements of quality imposed on the finished products allow only the addition of tiny quantities of Alfa fibers. Therefore, the proportion of Alfa fiber in nonwoven must be carefully studied. In this work, we examine the effect of Alfa fiber proportion on different physical and tensile nonwoven properties.

\subsection{Effect of Alfa Fiber Ratio on the Nonwoven Physical Properties}

Table 3 shows the mean of measuring the weight and the thickness of different nonwoven samples. The coefficients of variation (CV \%) are also summarized in Table 3. For each mixing fibers, a variation of the Alfa fiber proportion from $0 \%$ to $60 \%$ was done.

The weight and thickness of nonwoven manufactured vary with the Alfa fibers ratio in the mixture. For the same Alfa fibers ratio, data from Table 3 revealed that the weight of Alfa/Tencel has the lowest value and this of Alfa/Wool has the highest one. This same remark was observed for the thickness. We can observe also, from Table 3, that the weight of the same material blend changes with the Alfa fiber ratio. For the Alfa/Cotton blend for example, when the Alfa fiber ratio reach a maximum (60\%) the weight decrease and reach a value of 215,54 $\mathrm{g} / \mathrm{m}^{2}$. This variation is probably due to the difference of fiber density between the two components of blend. However, the density of chemically extracted Alfa fiber is 1.35 [22] smaller than cotton (1.5). 
Table 3. Thickness and weight of different nonwoven samples.

\begin{tabular}{|c|c|c|c|c|c|c|c|c|c|}
\hline & \multicolumn{5}{|c|}{ Weight $\left(\mathrm{g} / \mathrm{m}^{2}\right)$} & \multicolumn{4}{|c|}{ Thickness (mm) } \\
\hline & & Alfa/PES & Alfa/Cotton & Alfa/Tencel & Alfa/Wool & Alfa/PES & Alfa/Cotton & Alfa/Tencel & Alfa/Wool \\
\hline \multirow{2}{*}{0} & Mean & 252.51 & 219.4 & 206.96 & 351.66 & 1.58 & 1.41 & 1.59 & 3.85 \\
\hline & $\mathrm{CV}(\%)$ & 3.81 & 2.13 & 1.78 & 0.66 & 1.99 & 3.8 & 3 & 3.51 \\
\hline \multirow{2}{*}{10} & Mean & 251.60 & 218.11 & 204.12 & 355.65 & 1.54 & 1.44 & 1.50 & 4.10 \\
\hline & $\mathrm{CV}(\%)$ & 3.17 & 1.91 & 3.93 & 3.59 & 3.88 & 2.42 & 2.47 & 4.9 \\
\hline \multirow{2}{*}{20} & Mean & 250.46 & 217.08 & 204.33 & 353.08 & 1.6 & 1.37 & 1.58 & 3.99 \\
\hline & $\mathrm{CV}(\%)$ & 2.36 & 3.47 & 4.08 & 2.89 & 4.67 & 3.25 & 4.61 & 4.01 \\
\hline \multirow{2}{*}{30} & Mean & 249.86 & 216.15 & 204.15 & 353.22 & 1.56 & 1.41 & 1.54 & 3.97 \\
\hline & $\mathrm{CV}(\%)$ & 2.99 & 1.33 & 2.45 & 4.23 & 3.14 & 2.26 & 4.42 & 1.94 \\
\hline \multirow{2}{*}{40} & Mean & 248.06 & 216.33 & 205.09 & 352.43 & 1.53 & 1.44 & 1.5 & 3.86 \\
\hline & $\mathrm{CV}(\%)$ & 2.61 & 2.34 & 2.42 & 1.44 & 2.2 & 3.08 & 2.67 & 2.96 \\
\hline \multirow{2}{*}{50} & Mean & 246.3 & 215.94 & 206.01 & 355.2 & 1.54 & 1.48 & 1.62 & 4.15 \\
\hline & $\mathrm{CV}(\%)$ & 4.8 & 3.31 & 3.95 & 2.9 & 4.04 & 2 & 3.93 & 2.81 \\
\hline \multirow{2}{*}{60} & Mean & 246.85 & 215.54 & 203.33 & 354.71 & 1.55 & 1.49 & 1.53 & 3.99 \\
\hline & CV(\%) & 2.52 & 1.94 & 4.06 & 2.45 & 3.13 & 1.8 & 4.03 & 2.01 \\
\hline
\end{tabular}

The Figure 7 shows the variation plots of nonwoven fabric density $\left(\mathrm{g} / \mathrm{cm}^{3}\right)$ with the Alfa fibers ratio (\%) for different fibers mixture. We note that the nonwoven density of Alfa/PES and Alfa/Tencel do not vary significantly depending on the ratio increase of Alfa fibers in the mixture. This can be explained by the fact that the fibers densities have almost equal (Table 1). We can also observe clearly that the fabric density of Alfa/Cotton blend decreases with the increase of Alfa fibers ratio. This is due to the high cotton fibers density and fineness compared to those of Alfa fibers.

In the case of Alfa/Wool blend, no change was observed. But the fabric density of this blend is lower than the others because high mean length and low fineness of wool fibers.

Air permeability is one of the important properties which affect the performance of nonwovens used for filtration, insulation and drainage applications. The adiathermic capacity and air permeability are also considered to be important that affect the nonwoven used especially in the comfort functions. Figure 8 shows the variation in air permeability as a function of the Alfa fiber ratio in the mixture. We can observe that the air permeability increases with the Alfa fiber ratio in the Alfa/PES, Alfa/Cotton and Alfa/Tencel nonwoven samples. These results can be explained by the fineness fiber difference. Indeed, the Alfa fibers have a smaller fineness than that of fibers of polyester, cotton and tencel. The increase of Alfa fibers ratio raise the number and size of pores and increases the air permeability. In the case of Alfa/Wool blended nonwoven, the increase of Alfa fibers ratio reduces the air permeability which reaches a minimum at $30 \%$. Beyond this value, it increases again. This is due to the fact that the mean length and fineness of the wool fibers are higher than that of Alfa fibers. The fibers in mixture are arranged in the same direction and decrease the air permeability.

The adiathermic capacity reflects the thermal fabric resistance and radiance characteristics especially used in clothing industries and sportswears. Results given in Figure 9 indicate that the adiathermic capacity decreases with the Alfa fiber content. As generally observed, the increasing of the fabric porosity improves the nonwoven thermal resistance. The air imprisoned inside pores creates a thermal barrier. That's why Alfa/PES and Alfa/ Wool nonwoven have higher adiathermic property. We note that the polyester fibers used in this study were textured.

\subsection{Effect of Alfa Fibers Ratio in the Blend on the Tensile Properties of Needle-Punched Nonwoven}

Tensile properties are very important parameters that indicate nonwoven mechanical characteristics. Figure 10 and Figure 11 present the effect of Alfa fibers ratio on the nonwoven specific strength in machine direction and cross direction. We can observe clearly from results that nonwoven specific strength decreases with the increase 


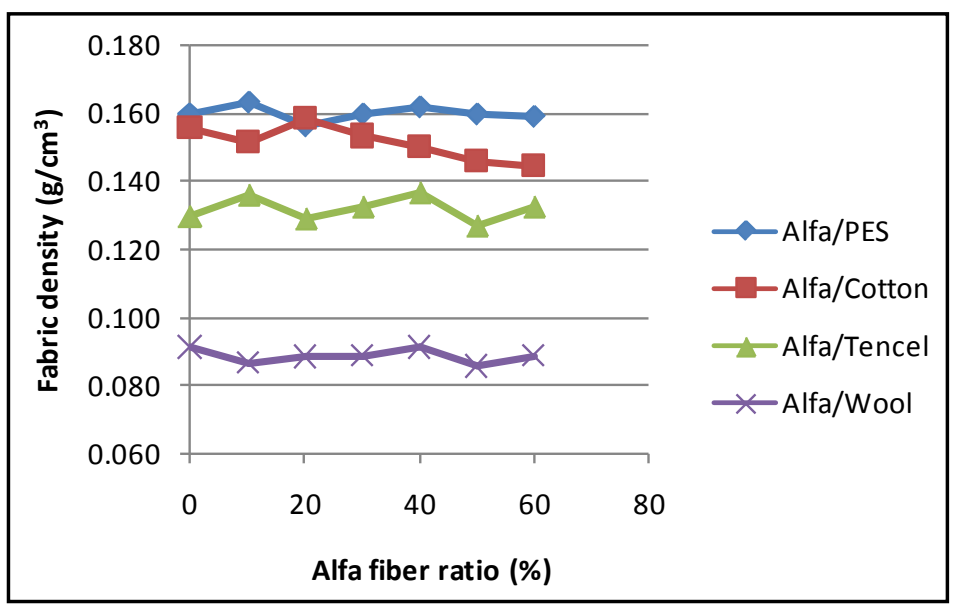

Figure 7. Variation of fabric density with the Alfa fibers ratio.

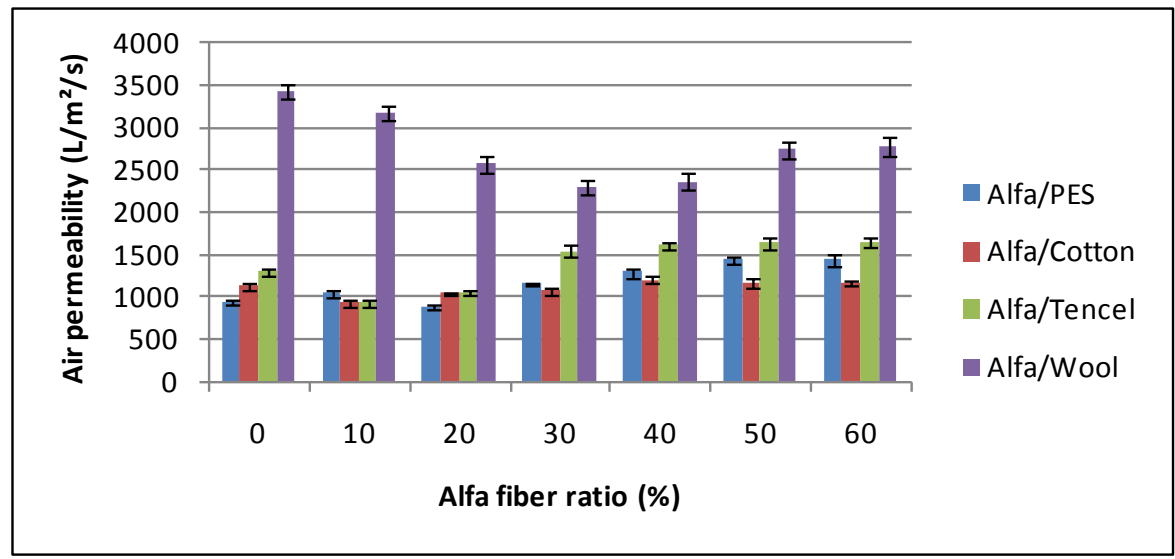

Figure 8. Variation of air permeability with Alfa fiber ratio.

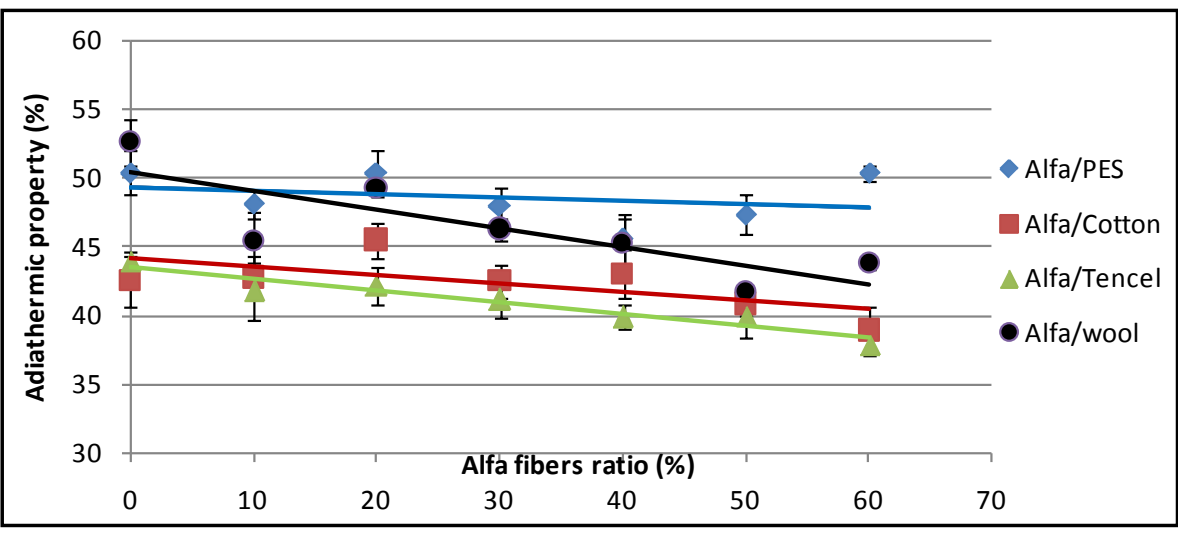

Figure 9. Variation of adiathermic capacity with Alfa fibers ratio.

of Alfa fibers ratio in the Alfa/PES, Alfa/Cotton, Alfa/Tencel and Alfa/Wool blend. This result is explained by the low tenacity of Alfa fibers despite its elongation is 18\% higher than cotton fibers, $14 \%$ than polyester and Tencel fibers and 15\% than wool fibers (Table 1). The results show that the increase of Alfa fibers ratio from $0 \%$ to $50 \%$ decreases the specific strength by $62 \%, 47 \%, 65 \%$ and $33 \%$, respectively, for Alfa/Cotton, Alfa/Tencel, Alfa/PES and Alfa/wool blends in the machine direction (MD). In the cross direction (CD), the breaking stress undergoes a decrease of $36 \%, 74 \%, 37 \%$ and $73 \%$, respectively, for the same mixtures. 


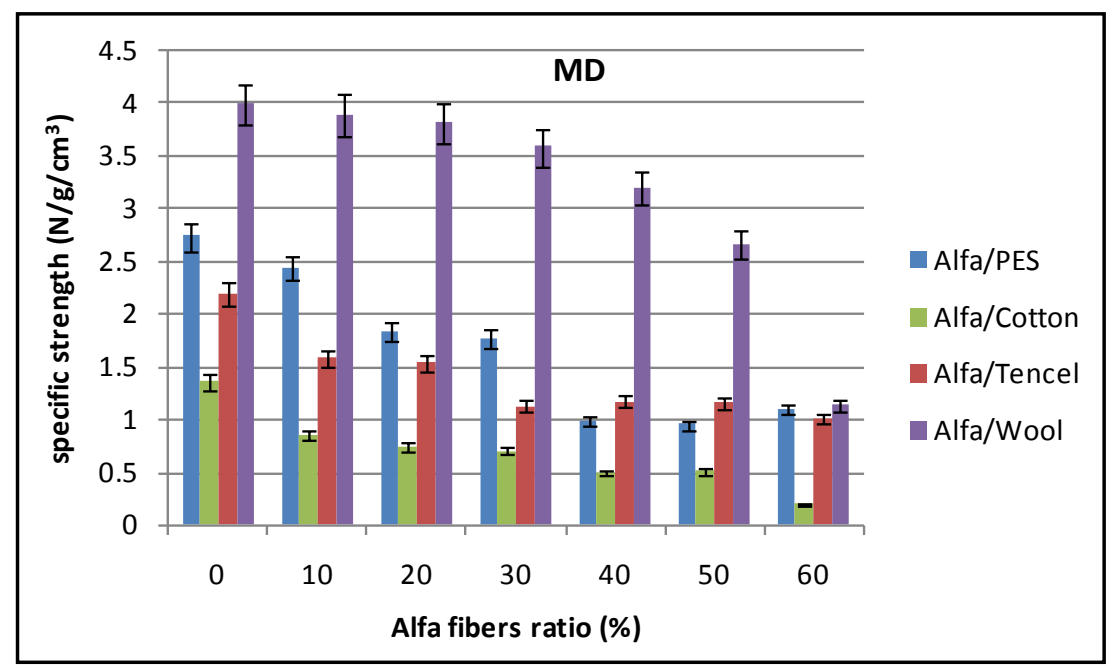

Figure 10. Specific strength in machine direction (MD) vs. Alfa fibers ratio.

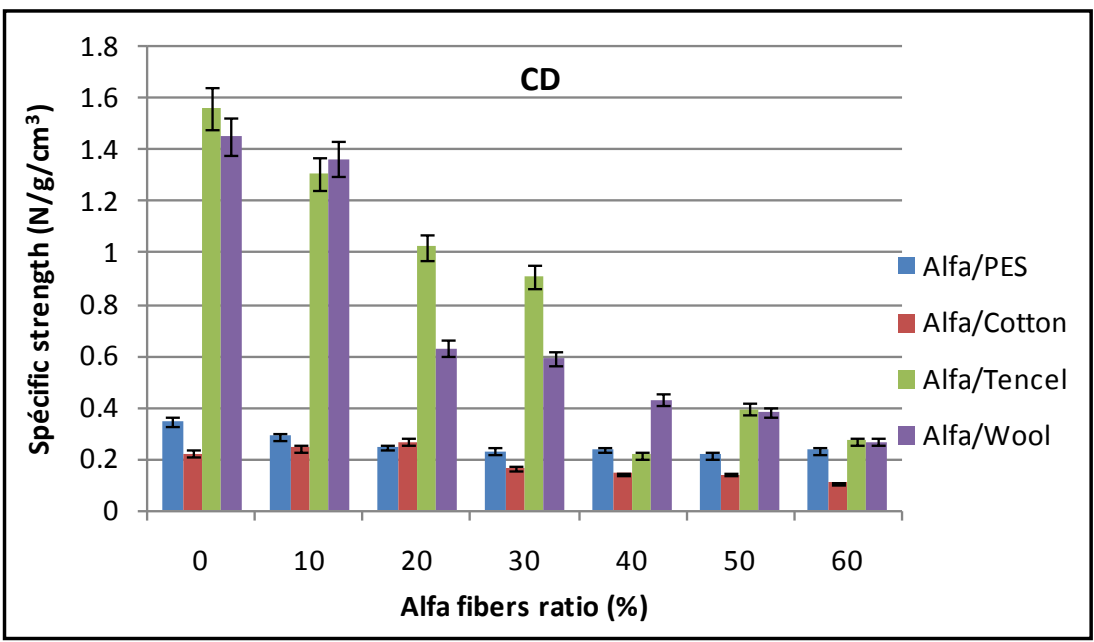

Figure 11. Specific strength in cross direction (CD) vs. Alfa fibers ratio.

On the other hand, two phenomenons are considered to explain nonwoven specific strength variation. Firstly, the penetration of barbed needles rearranges some fibers from horizontal position to vertical one depending on the fibers length. That's why the Alfa/wool nonwoven has a high specific strength. Secondly, the fiber tenacity and roughness promote a good strength.

Data comparison gleaned from both Figure 10 and Figure 11 exhibited that the specific strength in machine direction is higher than in cross direction for all nonwoven samples. This can be explained by the fact that, in machine direction the fibers are aligned leading to good mechanical properties.

The results given in Figure 12 revealed a decrease in elongation of the nonwoven made from different mixtures with increasing the Alfa fibers ratio, to the machine direction and the cross direction. Although, the elongation at break of Alfa fibers exceeds that of the used fibers, we notice that increasing the Alfa fibers ratio decreases the nonwoven elongation at break. These results can be explained by the surface roughness of Alfa fibers that do not promote slippage between fibers during the tensile test. Despite this decrease in elongation at break, we note that it remains relatively high (greater than $57 \%$ for different mixtures) and the nonwoven can withstand mechanical extensions before failure.

\section{Conclusions}

This study emphasizes the use of Alfa fibers in nonwoven which can lead to different useable products in order 


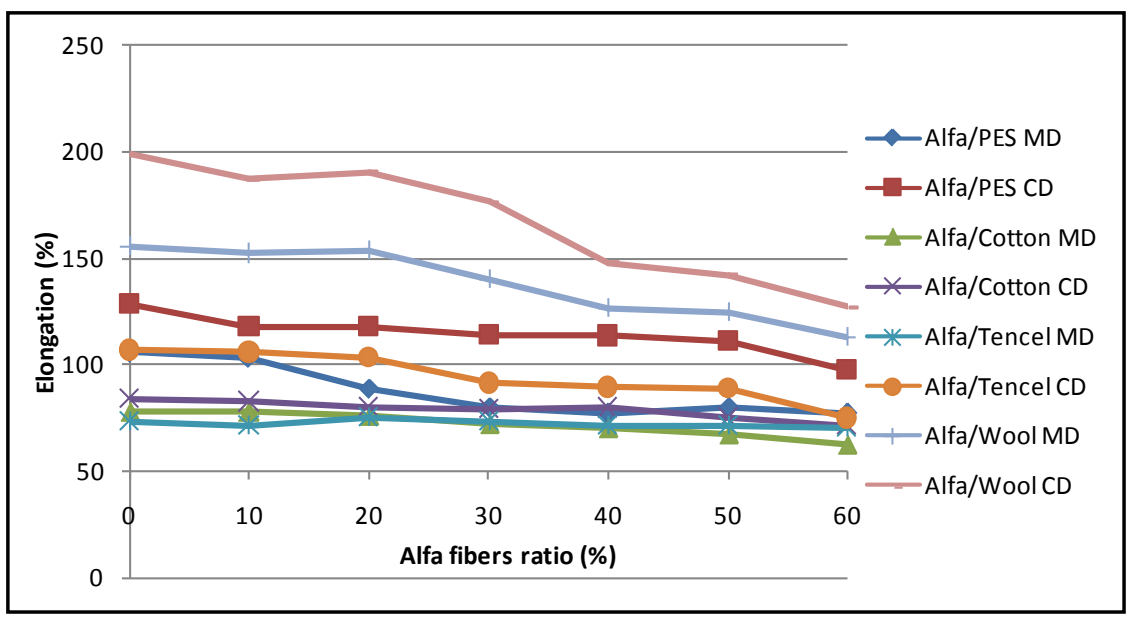

Figure 12. Variation curves of elongation (\%) vs. Alfa fibers ratio (\%).

to improve its added value. In this work, Alfa fibers were blended with other textile fibers such as cotton, polyester, tencel or wool. Mixtures have been carded on a cotton or wool card with proper adjustments and needled by a needle-punching machine. The physical and mechanical characterizations of nonwoven were discussed. We can conclude that:

- The air permeability increases with the increase of Alfa fibers ratio for the Alfa short fibers blended nonwoven. But, it decreases in case of Alfa/Wool blend.

- The nonwoven adiathermic capacity decreases with the addition of Alfa fibers.

- The mechanical properties degrade with the increasing of the Alfa fibers ratio.

- Nonwoven Alfa blended with wool fibers have the highest values of air permeability, specific strength in machine direction (MD) and the elongation at break for all the Alfa fibers blends.

\section{References}

[1] Yeo, Y.-J. and Jeon, D.-W. (2005) Effects of Chitosan Nonwoven Membrane on Periodontal Healing of Surgically Created One-Wall Intrabony Defects in Beagle Dogs. Journal of Biomedical Materials Research Part B: Applied Biomaterials, 72B, 86-93. http://dx.doi.org/10.1002/jbm.b.30121

[2] Kumar, R.N., Hee, K.C. and Rozman, H.D. (2005) Photo Fabrication of Biofiber-Based Polymer Matrix Composites. Journal of Applied Polymer Science, 95, 1493-1499. http://dx.doi.org/10.1002/app.21402

[3] Chen, Y., Chiparus, O., Sun, L., Negulescu, I., Parikh, D.V. and Calamari, T.A. (2005) Natural Fibers for Automotive Nonwoven Composites. Journal of Industrial Textiles, 35, 47-62. http://dx.doi.org/10.1177/1528083705053392

[4] Meng, J., Song, L. and Meng, J. (2006) Using Single-Walled Carbon Nanotubes Nonwoven Films as Scaffolds to Enhance Long-Term Cell Proliferation. Journal of Biomedical Materials Research Part A. 79A, 298-306. http://dx.doi.org/10.1002/jbm.a.30787

[5] Viala, X. and Andreopoulos, F.M. (2009) Novel Biomaterials for Cartilage Tissue Engineering. Current Rheumatology Reviews, 5, 51-57. http://dx.doi.org/10.2174/157339709787315366

[6] Anandjiwala, R.D. and Boguslavsky, L. (2008) Development of Needle-punched Nonwoven Fabrics from Flax Fibers for Air Filtration Applications. Textile Research Journal, 78, 614-624. http://dx.doi.org/10.1177/0040517507081837

[7] Sakthivel, S., Ezhil Anban, J.J. and Ramachandran, T. (2014) Development of Needle-Punched Nonwoven Fabrics from Reclaimed Fibers for Air Filtration Applications. Journal of Engineered Fibers and Fabrics, 9, 149-154.

[8] Jianyong, F. and Jianchun, Z. (2013) Oil Filtration Performance of a Hemp/Cotton Spunlaced Nonwoven. Textile Research Journal, 83, 2191-2203. http://dx.doi.org/10.1177/0040517513490058

[9] Cincik, E. and Koc, E. (2012) An Analysis on Air Permeability of Polyester/Viscose Blended Needle-Punched Nonwovens. Textile Research Journal, 82, 430-442. http://dx.doi.org/10.1177/0040517511414977

[10] Ammar, I., Ben Cheikh, R., Campos, A.R., Cunha, A.M. and Campos, A.R. (2006) Injection Molded Composites of Short Alfa Fibers and Biodegradable Blends. Polymer Composites, 27, 341-348.

[11] Sami, B.B. and Ben Cheikh, R. (2007) Influence of Fiber Orientation and Volume Fraction on the Tensile Properties of Unidirectional Alfa-Polyester Composite. Composites Science and Technology, 67, 140-147. 
[12] Samir, H., Benaboura, A., Pichavant, F.H., Nourmamodeb, A. and Castellan, A. (2002) Adding Value to ALFA Grass (Stipa tenacissima L.) Soda Lignin as Phenolic Resins: Lignin Characterization. Polymer Degradation and Stability, 76, 259-264.

[13] Omri, M.A., Triki, A., Guicha, M., Ben Hassen, M., Arous, M., El Hamzaoui, H.A. and Bulou, A. (2013) Effect of Wool and Thermo-Binder Fibers on Adhesion of Alfa Fibers in Polyester Composite. Journal of Applied Physics, 114, 224105.

[14] Triki, A., Omri, M.A., Guicha, M., Ben Hassen, M., Arous, M. and Kallel, A. (2014) Adhesion Characterization of Alfa Fibres in Unsaturated Polyester Matrix. International Journal of Applied Research on Textile, 2, 18-29.

[15] Paiva, M.C., Ammar, I., Campos, A.R., Cheikh, R.B. and Cunha, A.M. (2007) Alfa Fibers: Mechanical, Morphological and Interfacial Characterization. Composites Science and Technology, 67, 1132-1138. http://dx.doi.org/10.1016/j.compscitech.2006.05.019

[16] Russell, S. (2006) Handbooks of Nonwoven. The Textile Institute, University of Leeds, Leeds.

[17] Bel-Berger, P., Von Hoven, T., Ramaswamy, G.N., Kimmel, L. and Boylston, E. (1999) Cotton/Kenaf Fabrics: A Viable Natural Fabric. The Journal of Cotton Science, 3, 60-70.

[18] Chiparus, O.I. (2004) Bagasse Fiber for Production of Nonwoven Materials. Ph.D. Thesis, The School of Human Ecology, Romania.

[19] Berkalp, O.B. (2006) Air Permeability \& Porosity in Spun-Laced Fabrics. Fibers \& Textiles in Eastern Europe, 14, 81-85.

[20] Mohammadi, M., Banks-Lee, P. and Ghadimi, P. (2002) Air Permeability of Multilayer Needle Punched Nonwoven Fabrics: Experimental Method. Journal of Industrial Textiles, 32, 139-150. http://dx.doi.org/10.1106/152808302031161

[21] Ramaswamy, G.N., Sellers, T. and Tao, W. (2003) Kenaf Nonwovens as Substrates for Laminations. Industrial Crops and Products, 17, 1-8. http://dx.doi.org/10.1016/S0926-6690(02)00040-7

[22] Ghali, L., Zidi, M. and Roudesli, S. (2006) Physical and Mechanical Characterization of Technical Esparto (Alfa) fibers. Journal of Applied Sciences, 6, 2450-2455. http://dx.doi.org/10.3923/jas.2006.2450.2455

[23] Hearle, J.W.S., Grosberg, P. and Backe, S. (1969) Structural Mechanics of Fibers: Yarns and Fabrics. Wiley and Sons. New York. 